\title{
Ionospheric shock waves triggered by rockets
}

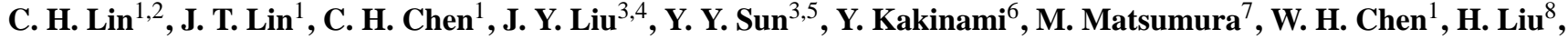 \\ and R. J. Rau ${ }^{1}$ \\ ${ }^{1}$ Department of Earth Sciences, National Cheng Kung University, Tainan, Taiwan \\ ${ }^{2}$ Earth Dynamic System Research Center, National Cheng Kung University, Tainan, Taiwan \\ ${ }^{3}$ Institute of Space Science, National Central University, Chung-Li, Taoyuan, Taiwan \\ ${ }^{4}$ National Space Organization, Hsinchu, Taiwan \\ ${ }^{5}$ CIRES, University of Colorado at Boulder, Boulder, CO, USA \\ ${ }^{6}$ School of Systems Engineering, Kochi University of Technology, Kami, Kochi, Japan \\ ${ }^{7}$ National Institute of Polar Research, Research Organization of Information and Systems, Tokyo, Japan \\ ${ }^{8}$ Department of Earth and Planetary Science, Faculty of Science, Kyushu University, Fukuoka, Kyushu, Japan
}

Correspondence to: C. H. Chen (koichi0925@gmail.com)

Received: 8 May 2014 - Revised: 15 August 2014 - Accepted: 18 August 2014 - Published: 16 September 2014

\begin{abstract}
This paper presents a two-dimensional structure of the shock wave signatures in ionospheric electron density resulting from a rocket transit using the rate of change of the total electron content (TEC) derived from groundbased GPS receivers around Japan and Taiwan for the first time. From the TEC maps constructed for the 2009 North Korea (NK) Taepodong-2 and 2013 South Korea (SK) Korea Space Launch Vehicle-II (KSLV-II) rocket launches, features of the V-shaped shock wave fronts in TEC perturbations are prominently seen. These fronts, with periods of $100-600 \mathrm{~s}$, produced by the propulsive blasts of the rockets appear immediately and then propagate perpendicularly outward from the rocket trajectory with supersonic velocities between $800-1200 \mathrm{~m} \mathrm{~s}^{-1}$ for both events. Additionally, clear rocket exhaust depletions of TECs are seen along the trajectory and are deflected by the background thermospheric neutral wind. Twenty minutes after the rocket transits, delayed electron density perturbation waves propagating along the bow wave direction appear with phase velocities of 800 $1200 \mathrm{~m} \mathrm{~s}^{-1}$. According to their propagation character, these delayed waves may be generated by rocket exhaust plumes at earlier rocket locations at lower altitudes.
\end{abstract}

Keywords. Ionosphere (ionosphere-atmosphere interactions; ionospheric disturbances; wave propagation)

\section{Introduction}

Studies have indicated that the exhaust plumes generated from shuttle launches or rockets carrying liquid fuel (LH2, LOX, $\mathrm{N}_{2} \mathrm{H}_{2}$ ) could result in ionospheric electron density depletion and/or airglow brightness along the ascending trajectories of the rockets (e.g., Booker, 1961; Bernhardt et al., 1975; Mendillo et al., 1975, 2008; Furuya and Heki, 2008; Ozeki and Heki, 2010; Meier et al., 2010). Following the observation of F-region depletion due to launch of Skylab mission, Benhardt et al. (1975) simulated the effect of rocket exhaust $\mathrm{H}_{2}$ in production of the $\mathrm{O}^{+}$depletion in the ionosphere and some $\mathrm{H}^{+}$reduction in the plasmasphere. Recently, largescale variations of the ionospheric electron density caused by rocket exhaust have been observed by using networks of GPS receivers showing the two-dimensional distribution of the depletions (Mendillo et al., 2008; Furuya and Heki, 2008; Ozeki and Heki, 2010).

In addition to the electron density depletion produced by chemical reactions, the shuttle blast plume could also affect the ionospheric electron density through interactions between the ionized and perturbed neutral particles. Observations taken away from the shuttle trajectory have revealed the travel ionospheric disturbances (TIDs) resulting from atmospheric acoustic-gravity waves (AGWs) excited by the space shuttle blast plume (e.g., Arendt, 1971; Noble, 1990; Li et al., 1994). Noble (1990) observed TIDs propagating further away (thousands of kilometers) from the shuttle trajectory 
with periods of $15-75 \mathrm{~min}$. Following observations of TIDs away from the trajectory, Calais and Minster (1996) observed the AGWs' effects along the shuttle launch path using a single ground-based GPS station for the first time and show that the enhanced total electron content (TEC) spectra are for those with periods of less than $10 \mathrm{~min}$ (600 s). More recently, Bowling et al. (2013) modeled such ionospheric perturbation produced by the space shuttle using a ray tracing model and taking into account of the perturbation amplitude of a moving source.

The observed AGWs-related TIDs and ionospheric perturbation waves due to the rocket passage are similar to the solar eclipse effect speculated by Chimonas and Hines (1970) that a localized heat sink traveling through a gravitationally stratified atmosphere with supersonic velocities may result in shock waves observable in the ionospheric plasma perturbation. In contrast to the heat sink resulting from a solar eclipse, the rocket exhaust plume may provide a heat source. The effect is analogous to the hydrodynamic systems (Comstock, 1967) where, if the source velocity exceeds the wave propagation speed, a "bow wave" formed by AGWs appears around the source region traveling away from the trajectory.

To examine the aforementioned AGWs due to heat released by rocket exhaust plumes and their propagation properties in the upper atmosphere, two-dimensional TEC maps derived from dense GPS networks in South Korea, Japan and Taiwan are utilized to study the AGWs signatures in the ionospheric plasma perturbation generated by the launches of the North Korea (NK) Taepodong-2 rocket in 2009 with an eastward trajectory and South Korea (SK) KSLV-II rocket in 2013 with a southward trajectory. From the time-varying two-dimensional TEC observation, the AGWs properties of ionospheric plasma perturbation due to the rockets are investigated.

\section{Observations and discussions}

\subsection{GPS-TEC observations for North Korean and South Korean rockets}

According to Ozeki and Heki (2010), who investigated the ionospheric plasma depletion due to the chemical released of the North Korea (NK) Taepodong-2 (T-2) rocket in 2009, the T-2 is a three-stage rocket that was launched at 02:30 UT 5 April from the east coast of North Korea and flew toward Japan. The trajectory of T-2 was obtained with radar tracking by the Japanese Ministry of Defense, showing that the satellite passed through the F-region over Japan Sea. By removing the $2 \mathrm{~h}$ linear curve-fitting of vertical TEC data using a second-order linear polynomial function, they found an ionospheric plasma depletion made by this rocket due to the exhaust plume of water vapor. As the AGWs feature in TEC is mainly the higher-frequency phenomenon compared with ionospheric electron density depletion caused by chemical reaction, the curve-fitting method, which may affect the high-frequency variations and their phases, is thus not suitable for this study. On the other hand, the rate of change of TEC corresponding to the sudden change of the ionospheric variations similar to the Doppler observation (cf. Liu et al., 2004, 2006) would be more suitable for detecting the shock wave features herein.

Figure 1a-f show the time series of the rate of change of TEC (hereinafter referred to as rTEC) derived from $30 \mathrm{~s}$ sampling of ground-based GPS data during the 2009 NK rocket passage. It is noted that the ionospheric height for converting slant to vertical TECs is set as $260 \mathrm{~km}$ in this analysis to avoid the misalignment of the TEC perturbation using multiple ground-based GPS stations (see Fig. 4 in Ozeki and Heki, 2010). Detailed time development variations of these wave propagations can be found in the Supplement (S1 - "NK_TIDmovie_260km"). From Fig. 1b, a V-shaped structure of positive rTECs indicating the shock wave signature appears at 02:35:30 UT while the rocket was at $260 \mathrm{~km}$ altitude traveling with a speed of $3.6 \mathrm{~km} \mathrm{~s}^{-1}$. The V-shaped structure in the southern boundary of the trajectory is clearer than that in the northern boundary. In the time frame 02:36:30-02:37:00 UT (Fig. 1c and d), rTECs along the rocket trajectory show a broad region of negative values accompanied by narrow positive rTEC bands located at their northern and southern outer boundaries. The narrow positive bands are outward propagating from the previous V-shaped structure, and a new V-shaped structure of positive rTEC band is formed at the rocket location (Fig. 1d). Around $20 \mathrm{~min}$ later, appearances of delayed waves propagating along the southeast (bow wave) direction of the trajectory are seen in Fig. 1e and $\mathrm{f}$.

Similar to the NK event, Fig. 1g-1 show the rTEC perturbation maps for the 2013 SK event. Detailed time development variations of these wave propagations can be found in the Supplement (S2 - "SK_TIDmovie_300km"). The SK KSLV-II launched at 07:00 UT (16:00 LT) 30 January 2013. According to the text description provided on the website of Korea Aerospace Research Institute (KARI, http://www. kslv.or.kr/lnch/lnch_obt.asp?mn=3), the KSLV-II had its first stage of rocket separation at 07:03:52 UT (16:03:52 LT) at $196 \mathrm{~km}$ altitude and $316 \mathrm{~km}$ away from the launch site. The second stage of rocket ignited at 07:06:35 UT at $303 \mathrm{~km}$ altitude, $1052 \mathrm{~km}$ away from the launch site, and separated at 07:09:00 UT, $2054 \mathrm{~km}$ away from the launch site. As the information of the SK rocket trajectory is limited on the KARI website, the rocket trajectory plotted in Fig. 1g1 could only be roughly taken from an illustration of a South Korean newspaper, Money Today, (http://news.mt.co. $\mathrm{kr} / \mathrm{mtview} \cdot \mathrm{php}$ ?no=2013012915110944605\&type=1). It is noted that since most of the GPS-TEC observations are taken after the rocket reaches $303 \mathrm{~km}$ altitude and maintains that altitude afterwards, the ionospheric height for calculating the sub-ionospheric points is set at $300 \mathrm{~km}$ for this analysis. 

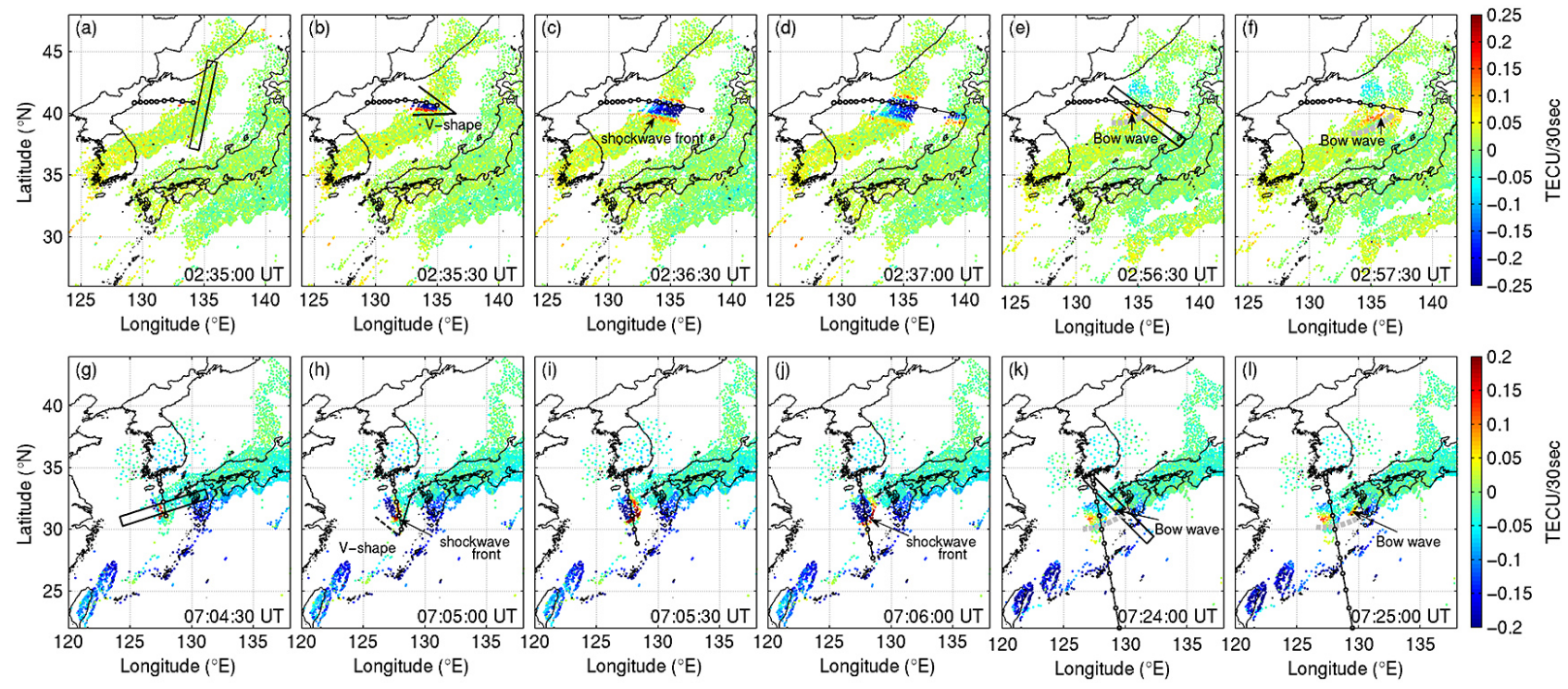

Figure 1. Snap shots of the rate of change of TEC (rTEC) indicating the shock and bow waves (enhanced rTECs in red color) and ionospheric depletions resulting from the rocket exhaust of the 2009 North Korea Taepodong-2 (a-f) and 2013 South Korea KSLV-II (g-l) rocket launches. The square boxes plotted in panels (a), (e), (g), (k) identify the regions for calculating the wave velocities shown in Figs. 4a and b, and 5a and c, respectively.

From Fig. 1g, similar V-shaped positive rTECs, i.e., the shock wave signature, appear to the west of the plotted trajectory and expand toward the east as seen from Fig. $1 \mathrm{~h}-\mathrm{j}$. As the shock wave signature should occur on the two sides of the rocket trajectory, it is likely that the actual rocket trajectory should be to the west of the reported trajectory plotted in Fig. 1g-1. Similar to the NK event, the SK event also shows the 20 min delayed rTEC perturbation waves propagating along the bow wave directions. Due to the limited view angle of the ground-based GPS receivers, the west side of the shock and bow waves could not be observed for the SK event.

The more prominent southward propagation of the shock wave and delayed waves in the bow wave direction is consistent with earlier studies suggesting that the acoustic-gravity waves in the ionosphere have a tendency towards equatorward propagation (e.g., Heki and Ping, 2005; Otsuka et al., 2006; Liu et al., 2011a). Simplified estimations of acoustic velocities and cutoff periods for the two events are calculated using parameters given by the empirical neutral atmosphere model, NRLMSISE-00 (Picone et al., 2002) (Fig. 2). The acoustic velocities for NK $(\sim 200 \mathrm{~km}$ altitude) and SK events $(\sim 300 \mathrm{~km})$ are 704 and $790 \mathrm{~m} \mathrm{~s}^{-1}$, respectively. The acoustic cutoff periods for NK and SK events are 642 and $726 \mathrm{~s}$, respectively.

To compare the properties of the perturbation waves shown in Fig. 1 with the estimations given in Fig. 2, we apply wavelet analysis (Torrence and Compo, 1998) on the rTECs for the NK event. We choose to present the NK event for comparison because it has wider spatial coverage of GPS-TEC observations. Figure 3 shows a snapshot of the two-dimensional rTEC variations at 02:37 UT, time evolutions of rTECs at different sub-ionospheric points (SIPs) and the associated wavelet spectrograms during the NK rocket flyby. In Fig. 3b, the SIP located in the middle of the trajectory shows clear negative rTECs due to the chemical reaction of the rocket exhaust, and the associated spectrogram indicates increases of amplitudes in all periods. For the observation taken at SIP away from the center of trajectory (Fig. 3c), a rapid rTEC increase is seen, followed by the rTEC depletions. The associated rTEC spectrum shows a greater enhancement for oscillation periods shorter than $600 \mathrm{~s}$ than those of longer periods. The effect of negative rTEC becomes much weaker for observations taken further away from the center of the trajectory (Fig. 3d and e), and mainly the oscillations of the shock wave fronts with periods of shorter than $600 \mathrm{~s}$ are enhanced. Neither the positive nor negative rTEC is seen for SIPs further away from the rocket trajectory (Fig. 3f), which could be treated as the background reference for comparisons with other subplots of Fig. 3 .

The N-shaped feature seen in Fig. $3 \mathrm{~d}$ and e is similar to the earlier report of shock-acoustic waves produced by rockets and earthquakes (Afraimovich et al., 2002, 2010). The enhanced spectra at shorter periods (less than $600 \mathrm{~s}$ ) for SIPs at the shock wave region fall within the acoustic cutoff period as shown in Fig. 2, and are consistent with those reported by Calais and Minster (1996). The negative rTECs caused by chemical reaction of rocket exhaust, on the other hand, mainly affect the oscillation with periods of greater than $600 \mathrm{~s}$ (Fig. $3 \mathrm{~b}$ and c). The rTEC line plot shown in Fig. 3c thus indicates the combined effect of $\mathrm{N}$-shaped shock waves and negative rTEC. 

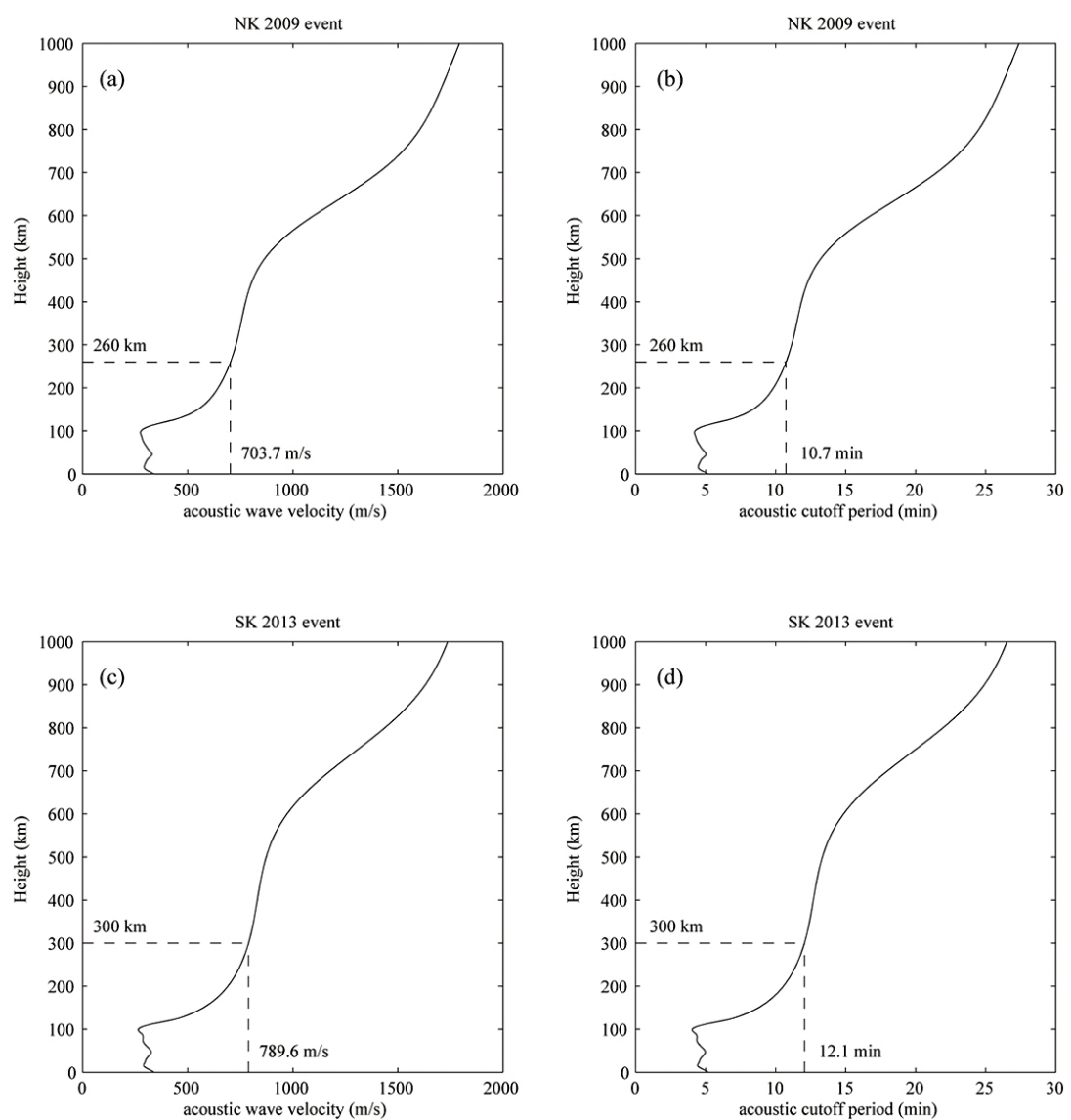

Figure 2. Estimation of averaged acoustic velocities and cutoff periods using NRLMSISE-00 model at rectangular boxes shown in Fig. 1 for the 2009 North Korean rocket launch (a and b) and for the 2013 South Korean rocket launch (c and d).

\subsection{Propagation velocities of TEC perturbations}

Figure $4 \mathrm{a}$ and $\mathrm{b}$ further show the time-distance rTEC map (rTEC velocity map) during the rocket-ascending period, indicating the velocities of the shock waves due to rocket exhaust blast and delayed rTEC perturbation waves in the bow wave direction, respectively. Figure $4 \mathrm{a}$ shows that there are three shock wave fronts produced by the rocket plume blast. The second and the third wave fronts are formed after the rocket has passed through, suggesting that the first wave is generated by the blast of the exhaust plume and the remaining exhaust plume acts as the heat source that continuously exerts perturbation waves (possibly dispersive AGWs) propagating perpendicularly outward from the rocket trajectory. The first shock wave with narrower wave front of $25 \mathrm{~km}$ (estimated from Supplement S1) has northward and southward propagating wave fronts with velocities of 928 and $1296 \mathrm{~m} \mathrm{~s}^{-1}$, respectively. The velocities reduce to around $800 \mathrm{~m} \mathrm{~s}^{-1}$ at a later time for the second and third shock wave fronts with broader wave fronts of $\sim 88$ and $105 \mathrm{~km}$, respectively.

Following the first shock wave, the signature of negative rTECs resulting from the chemical reaction of rocket exhaust is clearly seen trailing the rocket trajectory and has an initial northward propagation velocity of $155 \mathrm{~m} \mathrm{~s}^{-1}$ before reducing to $51 \mathrm{~m} \mathrm{~s}^{-1} 15 \mathrm{~min}$ later. The faster velocity of negative rTECs at the beginning may result from the combination of the propulsion velocity, neutral wind effect, and the molecular diffusion of the vapor (possibly $\mathrm{H}_{2}$ and $\mathrm{H}_{2} \mathrm{O}$ ) molecules. The later northward propagation of the negative rTECs is closer to the background neutral wind velocities obtained from the empirical horizontal wind model (HWM07) (Drob et al., 2008) around the rocket altitude showing a northward meridional wind of $20 \mathrm{~m} \mathrm{~s}^{-1}$ around 02:35-02:55 UT (11:35-11:55 LT). The discrepancy between propagating velocities of negative rTECs- and HWM07-predicted neutral wind velocity might also be because the actual neutral wind velocity is higher than the averaged value given by the climatology empirical model of HWM07.

Figure $4 \mathrm{~b}$ shows that the delayed rTEC perturbation waves traveling along the bow wave direction have velocities above $1000 \mathrm{~m} \mathrm{~s}^{-1}$, greater than those earlier shock wave fronts in Fig. 4a. The greater velocities of the delayed waves and their bow wave direction of propagation suggest that they might not be continued shock wave or acoustic-gravity wave fronts coming from the same source region. 

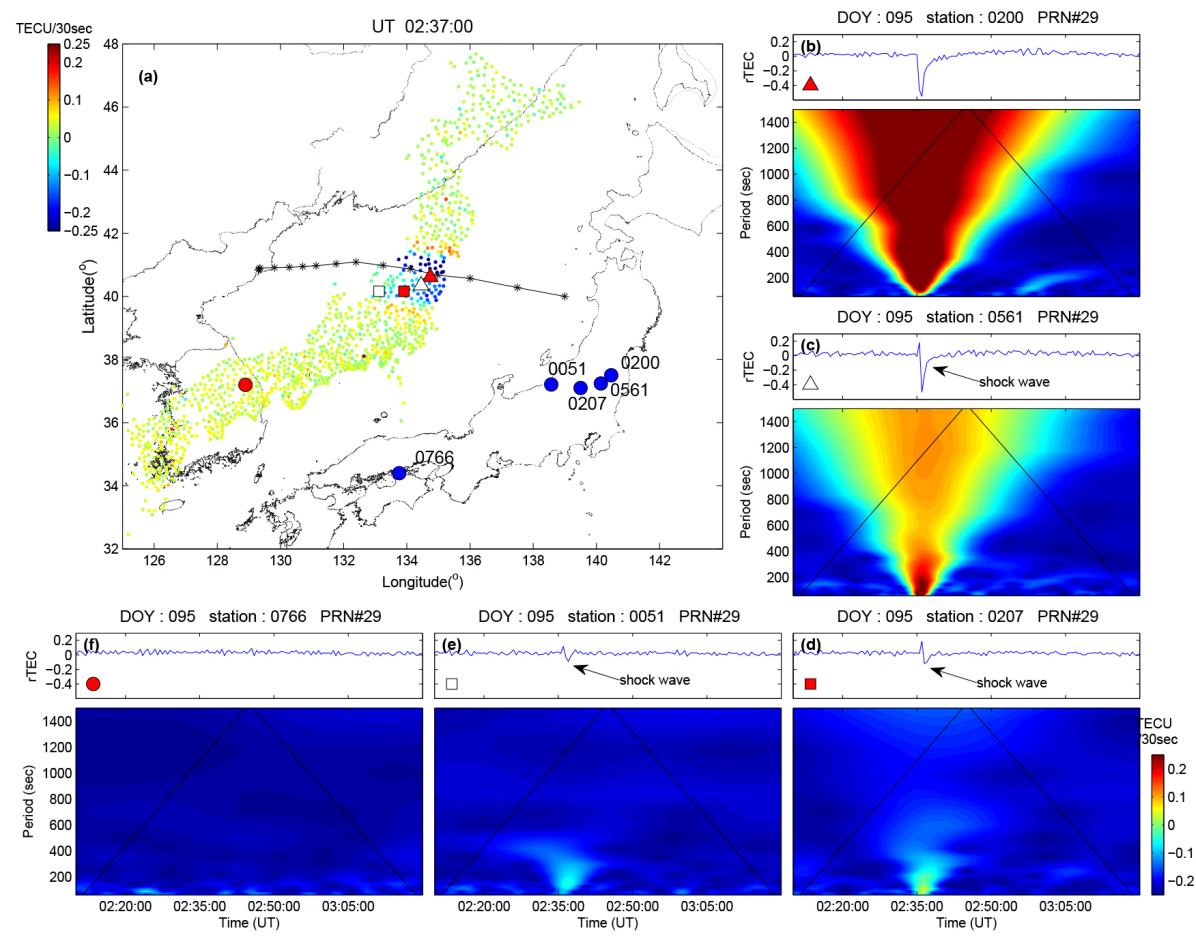

Figure 3. Two-dimensional rTEC maps derived from observations of GPS PRN\#29 and wavelet spectrums of sub-ionospheric points (SIPs) located (b) in the middle of the TEC depletion region due to the chemical reaction of rocket exhaust (denoted by the closed red triangle); (c) at the edge of the shock wave and depletion region (denoted by the open triangle); (d) and (e) at the shock wave locations (denoted by the closed and open red rectangles); (f) far away from the rocket trajectory (denoted by the red closed circle) for the 2009 North Korean rocket. Closed blue circles indicate the five corresponding ground-based GPS receivers. Black lines indicate the cone-of-influence of wavelet analysis, which indicates the maximum period of useful information at that particular time.

Similarly, the velocity map for the SK event shown in Fig. 5a also indicates the first narrow shock wave front in rTEC $(33 \mathrm{~km})$ propagating at velocity of $1331 \mathrm{~m} \mathrm{~s}^{-1}$ followed by two slower shock wave signatures traveling around $900 \mathrm{~m} \mathrm{~s}^{-1}$. All three shock wave fronts propagate perpendicularly outward (eastward) from the trajectory. The spatial width of first shock wave front is $\sim 33 \mathrm{~km}$ followed by the broader wave fronts of the second $(80 \mathrm{~km})$ and third $(110 \mathrm{~km})$ shock waves. The negative rTECs, due to the chemical reaction of rocket exhaust, again appear along with the shock wave signatures. Due to limited data coverage, the initial propagation velocity of the negative rTECs could not be estimated correctly, and the later negative rTECs propagate eastward with a velocity of $48 \mathrm{~m} \mathrm{~s}^{-1}$, almost identical to the zonal wind of $50 \mathrm{~m} \mathrm{~s}^{-1}$ predicted by HWM07. Figure $5 \mathrm{~b}$ indicates the appearance of delayed rTEC perturbation waves propagating in the bow wave direction with velocities around $800-1000 \mathrm{~m} \mathrm{~s}^{-1}$ after 07:20 UT. The delayed waves in Fig. 5b have similar properties as those in Fig. 4b. In general, the horizontal velocity exceeding $800 \mathrm{~m} \mathrm{~s}^{-1}$ presented in Figs. 4 and 5 is a little higher than the results of $700-800 \mathrm{~m} \mathrm{~s}^{-1}$ reported by Calais and Minster (1996) and Bowling et al. (2013).
The velocity maps shown in Figs. $4 \mathrm{a}$ and $5 \mathrm{a}$ are consistent with the hypothesis proposed by C.O. Hines (Arendt, 1971) about a shock wave traveling with diminishing velocities. Such variation is also seen by the coseismic ionospheric disturbances resulting from the great Tohoku earthquake of 2011 (cf. Liu et al., 2011b; Kakinami et al., 2013) where the initial velocity possibly induced by the Rayleigh wave may have exceeded $3 \mathrm{~km} \mathrm{~s}^{-1}$ followed by acoustic waves with $0.6-2 \mathrm{~km} \mathrm{~s}^{-1}$ velocities. Similar coseismicinduced two-mode waves were also reported for different events (e.g., Astafyeva et al., 2009). A theoretical simulation of TEC disturbances due to the Sumatra earthquake of 2004, reported by Shinagawa et al. (2007), also showed different modes of TEC propagating velocities. In their simulation of tsunami effects on the atmosphere, by using a vertical velocity in neutral atmosphere as lower boundary condition, they obtained the fast initial TID velocity of $675 \mathrm{~m} \mathrm{~s}^{-1}$ followed the slower second velocity of $350 \mathrm{~m} \mathrm{~s}^{-1}$. The results indicate that a single wave source may generate waves with different phase speeds. 

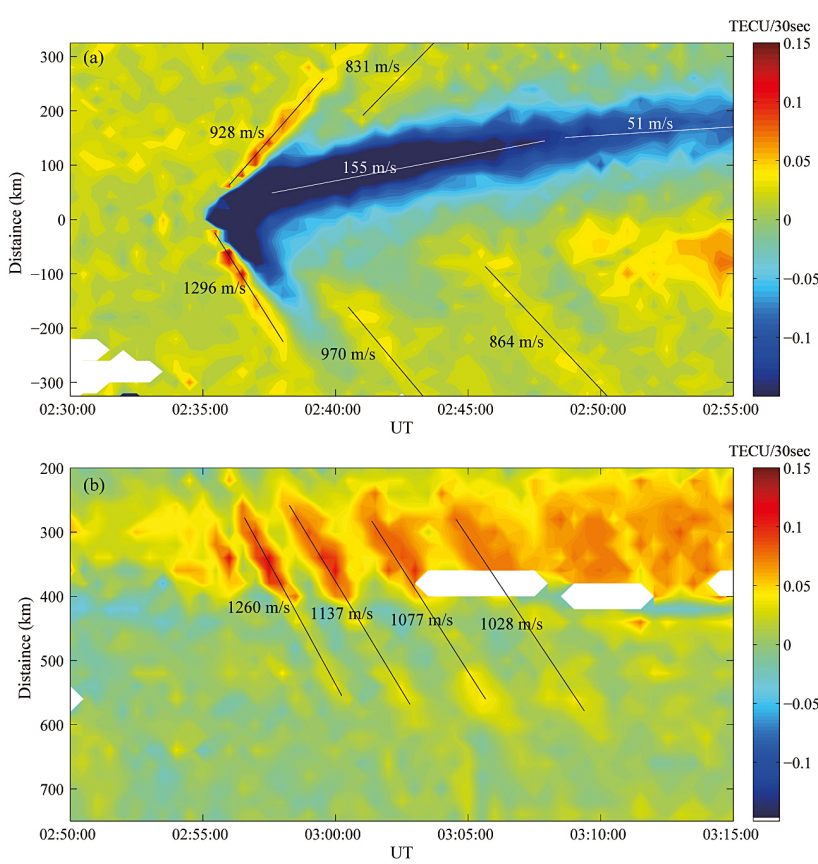

Figure 4. The rTEC time-distance velocity diagram (a) calculated from the center of the rectangle indicated in Fig. 1a (positive distance indicates northward propagation) from 02:30:0002:55:00 UT (11:30:00-11:55:00 LT) for the 2009 NK event; (b) velocity diagram of delayed waves along the bow wave direction calculated from the upper short side of the rectangle indicated in Fig. 1e (positive distance indicates southeastward propagation).

\section{Possible mechanism for delayed waves}

The appearances of the delayed perturbation waves shown in Figs. $4 \mathrm{~b}$ and $5 \mathrm{~b}$ have characteristics of bow waves as they mainly propagate along the direction of bow wave front with supersonic velocities of $800-1200 \mathrm{~m} \mathrm{~s}^{-1}$. The delayed waves are unlikely the continued or evolved local shock waves of the same origin, since the second and third shock waves shown in Figs. 4a and 5a are slower $\left(800-900 \mathrm{~m} \mathrm{~s}^{-1}\right.$ ) than the first arrival of delayed perturbation waves shown in Figs. $4 \mathrm{~b}$ and $5 \mathrm{~b}$ with most of their velocities exceeding $1000 \mathrm{~m} \mathrm{~s}^{-1}$. A possible source of the delayed waves may come from propagation of the AGWs generated at an earlier rocket stage/time (lower altitudes) that expand and propagate toward higher altitudes along with the rocket trajectories. It is worthwhile to note that the delayed perturbation waves of the two events both travel toward the southeast. For the SK event, it is possible that there might also be a southwest-propagating delayed wave but this goes beyond our GPS-TEC observation coverage. Nevertheless, the tendency toward southeastward propagation of delayed waves in the NK event is similar to bow waves resulting from the moon shadow of a solar eclipse reported by Liu et al. (2011a).

Heki and Ping (2005) and Otsuka et al. (2006) suggest that the ionospheric plasma perturbation would occur when
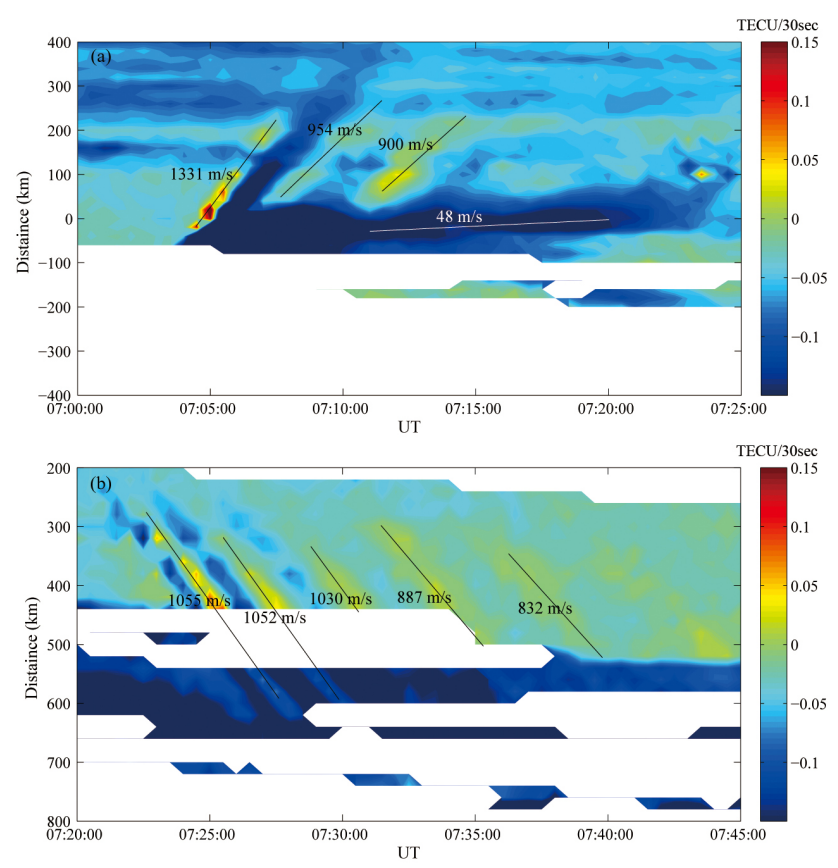

Figure 5. The rTEC time-distance velocity diagram (a) calculated from the center of the rectangle indicated in Fig. $1 \mathrm{~g}$ (positive distance indicates eastward propagation) from 07:00:00-07:25:00 UT (16:00:00-16:25:00 LT) for the 2013 SK event; (b) velocity diagram of delayed waves along the bow wave direction calculated from the upper short side of the rectangle indicated in Fig. 1k (positive distance indicates southeastward propagation).

the direction of seismic-related atmospheric AGWs propagates parallel to a magnetic field line and thereby the neutral density perturbation could affect the ionospheric plasma along magnetic field line more effectively. The illustrations in Fig. 6 demonstrate a possible effect of delayed bow waves shown in Figs. 4b and 5b. Figure 6a illustrates that the blast of the exhaust plume produces the V-shaped shock wave signatures in the ionosphere at the current stage (an example time tag of 02:35 UT at $260 \mathrm{~km}$ altitude in the illustration). In the meantime, the remaining exhaust plumes released at the earlier rocket locations/time (for example, at 02:30 and 02:33 UT) continuously exert perturbation waves propagating outward from them. As the energy of previously released exhaust plumes dissipate along with time, the perturbation wave fronts evolve from the V-shaped shock waves to the circular-shaped AGW fronts and thus propagate in the bow wave direction. If the delayed perturbation waves come from the same exhaust plume at the current stage $(\sim 260 \mathrm{~km}$ altitude) rather then the earlier stage as described above, the neutral density perturbation waves (indicated by green dashed arrows) would produce less prominent north-south asymmetry in ionospheric plasma perturbation as demonstrated in Fig. 6b. If the delayed plasma perturbation waves result from the neutral density perturbation at earlier stages at lower altitudes, it would be like the conditions shown in Fig. 6c. The neutral density perturbation waves at lower 

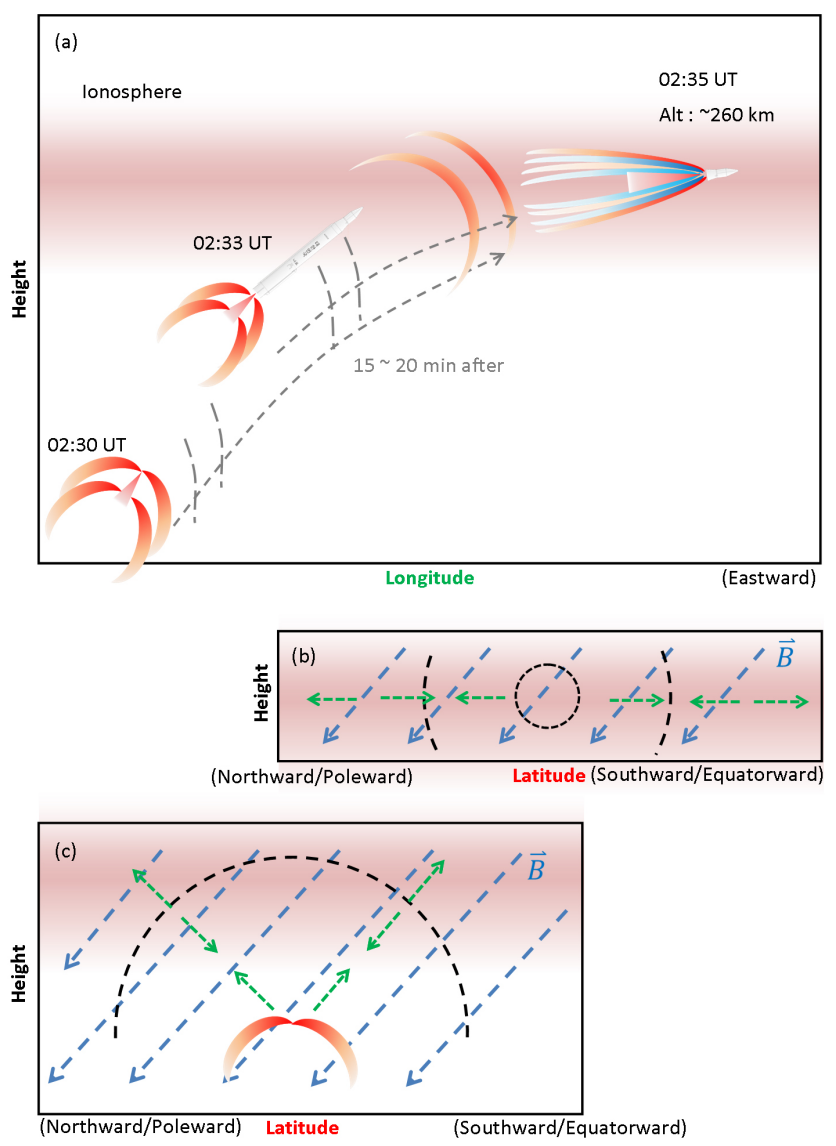

Figure 6. The illustrations demonstrate (a) the delayed bow waves generated by the exhaust plume released at earlier rocket locations at lower altitudes and propagated outward/upward from the source region toward higher altitudes (the altitudes and time tags are based on the $2009 \mathrm{NK}$ event); (b) the conditions for the neutral density perturbation waves generated by released plume at the rocket's current location where the outward propagation of neutral perturbation waves produce no north-south asymmetry in plasma perturbation waves; (c) the conditions for the neutral density perturbation waves coming from lower altitude which lead to prominent tendency toward equatorward/southward propagation of plasma perturbation waves. The blue dashed arrow lines indicate magnetic field lines, while the green dashed arrow lines indicate the disturbance waves.

altitude propagate outward and upward from the rocket exhaust source and result in a southward propagation tendency of plasma perturbation waves, since the field-aligned neutral density perturbation could affect the ionospheric plasma more easily than that perpendicular to the magnetic field. Observations of the southward propagation tendency of delayed plasma perturbation waves of the two events thus suggest that they are more likely coming from neutral density perturbations at earlier rocket locations at lower altitudes. Similar delayed, southward, and bow wave direction propagating plasma perturbation waves were reported by Liu et al. (2011a) during the solar eclipse event, where the AGWs are generated at stratospheric altitude and affect the ionospheric TEC.

The delayed plasma perturbation waves might also be possibly due to surface reflection or refraction from low velocity zones of neutral density perturbation waves. Li et al. (1994) and Calais and Minster (1996) both observed the second wave trains of ionospheric plasma perturbation after the shuttle passages. Li et al. (1994) attributed the effect to surface reflection of the rocket-generated perturbation waves, while Calais and Minster (1996) suggested the later wave train might result from neutral density perturbation waves propagating along a horizontal atmospheric waveguide. However, the velocity derived from horizontal waveguide proposed by Calais and Minster (1996) is fewer than $300 \mathrm{~m} \mathrm{~s}^{-1}$, much slower than our observations herein. On the other hand, we roughly estimate the minimum reflection time by taking into account the average sound speed and vertical distance between the rocket height and ground. The minimum reflection time of rocket-produced neutral density perturbation wave is $18 \mathrm{~min}$ for the NK event and $18.8 \mathrm{~min}$ for the SK event, comparable to the delay time observed in this study. Meanwhile, if the rocket-produced neutral density perturbation waves reflect from the surface or lower atmosphere, they also agree with the geometry conditions demonstrated in Fig. 6c and thus lead to a clear north-south asymmetry.

\section{Summary}

In summary, this study presents detailed two-dimensional GPS-TEC maps of the shock wave signature in ionospheric plasma as well as the delayed bow wave signatures that appeared $20 \mathrm{~min}$ after the rocket passages of both NK (westward trajectory) and SK (southward trajectory) events for the first time. Both shock wave and delayed bow wave signatures have initial velocities exceeding $1000 \mathrm{~m} \mathrm{~s}^{-1}$ followed by reduced velocities of $800-900 \mathrm{~m} \mathrm{~s}^{-1}$, and the equatorward propagations of shock wave velocities are more prominently seen than the poleward waves. The time series of twodimensional rTEC maps with shock and bow wave signatures provide a unique opportunity to estimate the associated propagation velocities. Such application could lead to further study of the propagation characteristics of the AGW signatures in the ionospheric plasma perturbation when rocket launches occur.

\section{The Supplement related to this article is available online at doi:10.5194/angeo-32-1145-2014-supplement.}

Acknowledgements. This work is supported by the Taiwan National Science Council under project nos. NSC 100-2628-M-006002-MY3, 103-2111-M-006-003-MY3, and 103-2111-M-006-001- 
MY2. This research is, in part, supported by the Ministry of Education, Taiwan under the Aim for the Top University Project to the National Cheng Kung University (NCKU). Additional support for C. H. Lin was provided by the NICT international exchange program to Kyushu University, Japan during October-December 2012, and the manuscript was first drafted on 27 March 2013. H. Liu acknowledges support by JSPS grant-in-aid for scientific research (B) (25800274). GPS data are provided by International GNSS Service, Japan GEONET, and the Central Weather Bureau of Taiwan.

Topical Editor K. Hosokawa thanks Y. Otsuka and one anonymous referee for their help in evaluating this paper.

\section{References}

Afraimovich, E. L., Kosogorov, E. A., and Plotnikov, A. V.: ShockAcoustic Waves Generated during Rocket Launches and Earthquakes, Cosmic Res., 40, 241-254, 2002.

Afraimovich, E. L., Feng, D., Kiryushkin, V. V., and Astafyeva, E. I.: Near-field TEC response to the main shock of the 2008 Wenchuan earthquake, Earth Planets Space, 62, 899-904, 2010.

Arendt, P. R.: Ionospheric undulations following Apollo 14 launching, Nature, 231, 438-439, doi:10.1038/231438a0, 1971.

Astafyeva, E., Heki, K., Kiryushkin, V., Afraimovich, E., and Shalimov, S.: Two-mode long-distance propagation of coseismic ionosphere disturbances, J. Geophys. Res., 114, A10307, doi:10.1029/2008JA013853, 2009.

Bernhardt, P. A., Park, C. G., and Banks, P. M.: Depletion of the F2 region ionosphere and the protonosphere by the release of molecular hydrogen, Geophys. Res. Lett., 2, 341-344, doi:10.1029/GL002i008p00341, 1975.

Booker, H. G.: A local reduction of F-region ionization due to missile transit, J. Geophys. Res., 66, 1073-1079, 1961.

Bowling, T., Calais, E., and Haase, J. S.: Detection and modeling of the ionospheric perturbation caused by a Space Shuttle launch using a network of ground-based Global Positioning System stations, Geophys. J. Int., 192, 1324-1331, doi:10.1093/gji/ggs101, 2013.

Calais, E. and Minster, J. N.: GPS detection of ionospheric perturbations following a Space Shuttle ascent, Geophys. Res. Lett., 23, 1897-1900, 1996.

Chimonas, G. and Hines, C. O.: Atmospheric Gravity Waves Induced by a Solar Eclipse, J. Geophys. Res., 75, 875-875, doi:10.1029/JA075i004p00875, 1970.

Comstock, J. P.: Principles of Naval Architecture, Society of Naval Architects and Marine Engineers, New York, 1967.

Drob, D. P., Emmert, J. T., Crowley, G., Picone, J. M., Shepherd, G. G., Skinner, W., Hays, P., Niciejewski, R. J., Larsen, M., She, C. Y., Meriwether, J. W., Hernandez, G., Jarvis, M. J., Sipler, D. P., Tepley, C. A., O'Brien, M. S., Bowman, J. R., Wu, Q., Murayama, Y., Kawamura, S., Reid, I. M., and Vincent, R. A.: An empirical model of the Earth's horizontal wind fields: HWM07, J. Geophys. Res., 113, A12304, doi:10.1029/2008JA013668, 2008.

Furuya, T. and Heki, K.: Ionospheric hole behind an ascending rocket observed with a dense GPS array, Earth Planets Space, 60, 235-239, 2008.

Heki, K. and Ping, J.: Directivity and apparent velocity of the coseismic ionospheric disturbances observed with a dense GPS array, Earth Planet. Sci. Lett., 236, 845-855, doi:10.1016/j.eps1.2005.06.010, 2005.

Kakinami, Y., Kamogawa, M., Watanabe, S., Odaka, M., Mogi, T., Liu, J.-Y., Sun, Y.-Y., and Yamada, T.: Ionospheric ripples excited by superimposed wave fronts associated with Rayleigh waves in the thermosphere, J. Geophys. Res., 118, 905-911, doi:10.1002/jgra.50099, 2013.

Li, Y. Q., Jacobson, A. R., Carlos, R. C., Massey, R. S., Taranenko, Y. N., and Wu, G.: The blast wave of the Shuttle plume at ionospheric heights, Geophys. Res. Lett., 21, 2723-2740, 1994.

Liu, J. Y., Lin, C. H., Tsai, H. F., and Liou, Y. A.: Ionospheric solar flare effects monitored by the ground-based GPS receivers: Theory and observation, J. Geophys. Res., 109, A01307, doi:10.1029/2003JA009931, 2004.

Liu, J. Y., Lin, C. H., Chen, Y. I., Lin, Y. C., Fang, T. W., Chen, Chen, Y. C., and Hwang, J. J.: Solar flare signatures of the ionospheric GPS total electron content, J. Geophys. Res., 111, A05308, doi:10.1029/2005JA011306, 2006.

Liu, J. Y., Sun, Y. Y., Kakinami, Y., Chen, C. H., Lin, C. H., and Tsai, H. F.: Bow and Stern Waves Triggered by the Moon's Shadow Boat, Geophys. Res. Lett., 38, L17109, doi:10.1029/2011GL048805, 2011a.

Liu, J.-Y., Chen, C.-H., Lin, C.-H., Tsai, H.-F., Chen, C.-H., and Kamogawa, M.: Ionospheric disturbances triggered by the 11 March 2011 M9.0 Tohoku earthquake, J. Geophys. Res., 116, A06319, doi:10.1029/2011JA016761, 2011b.

Mendillo, M., Hawkins, G. S., and Klobuchar, J. A.: A sudden vanishing of the ionospheric F region due to the launch of Skylab, J. Geophys. Res., 80, 2217-2225, 1975.

Mendillo, M., Smith, S., Coster, A., Erickson, P., Baumgardner, J., and Martinis, C.: Man-made space weather, Space Weather, 6, S09001, doi:10.1029/2008SW000406, 2008.

Meier, R. R., Plane, J. M. C., Stevens, M. H., Paxton, L. J., Christensen, A. B., and Crowley, G.: Can molecular diffusion explain Space Shuttle plume spreading?, Geophys. Res. Lett., 37, L08101, doi:10.1029/2010GL042868, 2010.

Noble, S. T.: A large-amplitude traveling ionospheric disturbance excited by the Space Shuttle during launch, J. Geophys. Res., 95, 19037-19044, 1990.

Otsuka, Y., Kotake, N., Tsugawa, T., Shiokawa, K., Ogawa, T., Effendy, Saito, S., Kawamura, M., Maruyamam, T., Hemmakorn, N., and Komolmis, T.: GPS detection of total electron content variations over Indonesia and Thailand following the 26 December 2004 earthquake, Earth Planets Space, 58, 159-165, 2006.

Ozeki, M. and Heki, K.: Ionospheric holes made by ballistic missiles from North Korea detected with a Japanese dense GPS array, J. Geophys. Res., 115, A09314, doi:10.1029/2010JA015531, 2010.

Picone, J. M., Hedin, A. E., Drob, D. P., and Aikin, A. C.: NRLMSISE-00 empirical model of the atmosphere: Statistical comparisons and scientific issues, J. Geophys. Res., 107, 1468, doi:10.1029/2002JA009430, 2002.

Shinagawa, H., Iyemori, T., Saito, S., and Maruyama, T.: A numerical simulation of ionospheric and atmospheric variations associate with the Sumatra earthquake on December 26, 2004, Earth Planets Space, 59, 1015-1026, 2007.

Torrence, C. and Compo, G. P.: A Practical Guide to Wavelet Analysis, B. Am. Meteorol. Soc., 79, 61-78, doi:10.1175/1520 0477(1998)079<0061:APGTWA>2.0.CO;2, 1998. 